Revista Brasileira de

Engenharia Agrícola e Ambiental

v. 15 , n.6, p.639-645, 2011

Campina Grande, PB, UAEA/UFCG - http://www.agriambi.com.br

agriambi Protocolo 027.10 - 04/03/2010 • Aprovado em 14/03/2011

\title{
Aplicação da cinza da casca do arroz em argamassas de assentamento
}

\author{
Izabelle M. T. Bezerra ${ }^{1}$, Jozilene Souza ${ }^{2}$, João B. Q . de Carvalho ${ }^{1} \&$ Gelmires A. N eves ${ }^{3}$
}

\section{RESUMO}

A cinza produzida pela queima da casca do arroz tem potencial para ser utilizada na confecção de argamassas por possuir, em sua constituição, alto teor de sílica $\left(\mathrm{SiO}_{2}\right)$, podendo ser utilizada também como material pozolânico. Esta pesquisa objetivou verificar a viabilidade da utilização da cinza da casca do arroz (CCA) em argamassas de assentamento. Realizou-se a caracterização química e mineralógica da CCA e se determinou o índice de atividade pozolânica. Para as argamassas foi determinado o índice de consistência e, em seguida, confeccionados corpos de prova de referência (sem CCA) e também com percentuais de $6,9,15,20$ e $30 \%$ de CCA, como substituição parcial do cimento, para o traço 1:2:9, em massa, e ensaiados após períodos de cura de 28,63 e 91 dias para determinação da densidade de massa no estado endurecido, absorção de água e resistência à compressão simples. Os resultados mostram que a CCA apresenta pozolani cidade e os corpos de prova com incorporação da CCA forneceram valores superiores aos de referência com relação às propriedades físicas e mecânicas, devido à provável ocorrência das reações pozolânicas e que a utilização da CCA é viável, tanto do ponto de vista técnico quanto ecológico.

Palavras-chave: argamassa de assentamento, pozolanas, resíduos

\section{Application of the rice husk ash in mortars for bricklaying}

\begin{abstract}
The ash produced by the burning of the rice husk presents potential for application in mortar production because has high silica content $\left(\mathrm{SiO}_{2}\right)$, and so it can be used as pozzolan. This research aimed to verify the viability of rice husk ash ( $\mathrm{RHA}^{2}$ ) added to mortars for bricklaying. Chemical and mineralogical characterization of RHA was initially carried out and the pozzolanic activity was determined. For the production of mortars, the consistence of each mixture studied was determined and then reference mortars (without CCA) and mortars with incorporated RHA were produced with 6, 9, 15, 20 and 30\% of RH A in partial substitution of cement for mortar 1:2:9 (mass ratio), in curing period of 28,63 and 91 days for determination of mass density in the hardened material, water absorption and compressive strength. The results obtained allowed it to conclude that RHA presents pozzolanicity and the mortars with incorporated RHA had values superior to the reference mixtures in relation to the physical and mechanical performance probably due to pozzolanic reactions and that the utilization of RHA in mortars is feasible in relation to the technical and ecological aspects.
\end{abstract}

Key words: mortars for bricklaying, pozolans, residues

PPGECA/UFCG, Av. A prígio Veloso 882, Bodocongó, Campina Grande, PB, CEP 58429-140. Fone: (83) 3310-1050 E-mail: izabelle_marie@yahoo.com.br; jbqc@bol.com.br

2 IFRR, Avv. Capitão Júlio Bezerra 1392, Aparedacida, Boa Vista, RR. Fone/Fax: (095) 3624-1224 E-mail: jozilenedesouza@yahoo.com.br 3 UAEMa/U FCG. Fone: (83) 3310-1183, Fax: (83) 3310-1178. E-mail: gelmires@dema.ufcg.edu.br 


\section{INTRODUÇÃO}

A reciclagem de resíduos é uma maneira de se diversificar a oferta de matéria-prima para a utilização como material de construção, viabilizando reduções de custo. A reciclagem de materiais, tais como entulhos, resíduos agrícolas, resíduos industriais e resíduos de mineração, entre outros, contribui para a preservação ambiental (Lima et al., 2008).

A geração de resíduos na agroindústria tem causado grande preocupação, visto que seu descarte vem desencadeando diversos problemas ambientais, como a poluição do solo, de mananciais e até mesmo do ar. Um dos setores mais abrangentes para aplicação desses resíduos é o da construção civil, em concretos e argamassas tornando possível, através de estudos, a destinação final adequada para esses resíduos.

Para que sejam utilizados na construção civil, os novos materiais devem atender às exigências físicas e mecânicas, de acordo com a normatização como, por exemplo, serem resistentes, duráveis e trabalháveis, entre outras características desejáveis, para que sejam superiores ou similares aos produtos já existentes no mercado (Ghavami \& Marinho, 2005; Barboza et al., 2008; Lima \& Rossignolo, 2010). Essas exigências são necessárias visto que o setor da construção civil necessita oferecer, ao mercado, materiais que tenham boa qualidade e vida prolongada.

As cinzas minerais oriundas de diferentes atividades agroindustriais destacam-se entre os resíduos, que apresentam altas porcentagens de sílica e de outros óxidos, podendo ser então utilizadas como pozolanas (Paula et al., 2009).

Os resíduos vegetais como a cinza da casca do arroz (CCA), vêm sendo estudados por vários pesquisadores (Bui et al., 2005; Della et al., 2005; Agarwal, 2006; Nair et al., 2006; Di Campos et al., 2008; Ganesan et al., 2008; Menezes et al., 2008; Kieling et al., 2009; Ramezanianpour et al., 2009; Rashid et al., 2010; Zerbino et al., 2011) os quais observaram que esta cinza apresenta bons resultados em diversas aplicações, como por exemplo, quando utilizada em argamassas e concretos.

A CCA possui, como maior componente químico, o dióxido de silício $\left(\mathrm{SiO}_{2}\right)$, variando entre 74 a 97\%, independendo do processo de queima (Tashima et al., 2004). O elevado teor de sílica torna a CCA valorizada, mas este resíduo só terá alto valor econômico se tiver alta qualidade, caracterizada pela elevada superfície específica, tamanho e pureza de partícula, podendo ser usado em diversas aplicações assim como em substituição parcial do cimento, em produtos da construção civil (Foletto et al., 2005).

A utilização de pozolanas em substituição parcial do cimento deve-se à presença de fases ativas em sua constituição química. A CCA quando reduzida a pó fino em presença de água e à temperatura ambiente, solubiliza em meio alcalino e reage com íons $\mathrm{Ca}^{+2}$ para formar silicatos de cálcio hidratados $(\mathrm{C}-\mathrm{S}-\mathrm{H})$, o C-S-H formado nestas reações pozolânicas é similar ao C-S-H produzido nas reações de hidratação do cimento Portland e o hidróxido de cálcio formado durante a hidratação do cimento Portland é a principal fonte de cálcio para as reações pozolânicas (Cordeiro et al., 2009a). A reação pozolânica tem como resultado a produção de fases químicas com maior estabilidade e poder aglomerante, sendo os principais responsáveis pela resistência das pastas de cimento hidratadas (Carmo \& Portella, 2008).

Depois de certo tempo a sílica deixa de reagir quimicamente, de maneira significativa como aglomerante e passa a atuar fisicamente, como filler inerte, através do efeito filler. As pozolanas finamente pulverizadas possuem ação física, uma vez que atuam nos concretos e argamassas como material de preenchimento melhorando o empacotamento do sistema (Menezes et al., 2009). No efeito filler o material fino preenche os vazios entre as partículas maiores de cimento, sendo também responsável pelo aumento da fluidez da pasta de cimento com relações água/cimento muito baixas (Toralles-Carbonari et al., 2010).

Na cinza amorfa com características pozolânicas, fatores como temperatura de queima, taxa de aquecimento, tempo de residência e ambiente de queima (disponibilidade de oxigênio), são responsáveis pela reatividade da cinza, pois influenciam na forma estrutural da sílica, na superfície específica das partículas e no teor de carbono remanescente (Cordeiro et al., 2009b).

A superfície específica da CCA tem grande influência na atividade pozolânica em virtude de estar diretamente correlacionada à finura do material, afetando o grau de atividade pozolânica; este comportamento é influenciado pela distribuição, forma e rugosidade superficial das partículas e pela distribuição dos poros existentes (Tiboni, 2007).

As características da CCA podem variar bastante, dependendo do processo de queima ao qual a casca é submetida (Silva et al., 2007). Quando produzida a partir de queima controlada com temperatura inferior a $600{ }^{\circ} \mathrm{C}$, a CCA possui, em sua morfologia, a presença de sílica no seu estado amorfo a qual por sua vez, promove maior reatividade com o cimento e a cal (Nair et al., 2008). Algumas pesquisas comprovam que as cinzas, embora originadas de processos de queima não controlados, podem apresentar características pozolânicas satisfatórias (Sensale, 2006; Pouey et al., 2007; Isaia et al., 2010; Rodrigues \& Beraldo, 2010).

A atividade pozolânica da CCA também está relacionada à composição morfológica e ao tempo de moagem desta cinza (Tashima et al., 2004). A temperatura de queima da casca de arroz influencia diretamente o tempo de moagem da CCA, visto que o aumento da temperatura provoca o agrupamento das partículas sendo necessário um tempo de moagem maior ou uma relação maior entre o peso de bolas do moinho e a quantidade a ser moída.

O aproveitamento da CCA é importante para o meio ambiente de vez que, quando descartada, provoca poluição por apresentar, em sua constituição, certa quantidade de carbono residual. A cinza é considerada altamente prejudicial para a saúde humana, devido ao elevado teor de sílica que pode ocasionar, quando de grande exposição, uma afecção pulmonar conhecida como "silicose".

Para o desenvolvimento desta pesquisa utilizou-se a cinza da casca do arroz proveniente da queima da casca do arroz sem controle de temperatura e a céu aberto, do município de Caicó, $\mathrm{RN}$, com o propósito de caracterizar e avaliar o desempenho deste resíduo, em argamassas de assentamento. 


\section{Material e MÉTODOS}

Neste trabalho os materiais utilizados para confecção das argamassas foram: cimento Portland CP II F - 32 da marca CIMPOR Brasil, por não conter pozolana em sua constituição, cal hidratada Megaó, areia do tipo média proveniente do rio Paraíba, passada em peneira ABNT n ${ }^{\circ} 4$ (abertura de $4,8 \mathrm{~mm}$ ) com módulo de finura de 2,4\% e diâmetro máximo de $4,8 \mathrm{~mm}$, cinza da casca do arroz resultante da queima a céu aberto da casca do arroz, sendo a cinza originada da cidade de Caicó, $\mathrm{RN}$, posteriormente passada em peneira $\mathrm{ABNT}^{\circ} 200$ (abertura de 0,074 mm) e água potável fornecida pela distribuidora local. Quando chegaram ao laboratório, os materiais cimento, cal e CCA foram acondicionados em sacos plásticos devidamente lacrados.

A cinza da casca do arroz foi caracterizada através de determinação das propriedades físicas (massa unitária e superfície específica pelo método de Blaine), composição química por fluorescência de raios X (Shimadzu EDX-90), difração de raios X (Shimadzu, XRD 6000), análise térmica gravimétrica (BP Engenharia RB3020) e distribuição de tamanho de partículas (Cilas, 1064LD).

Para determinação do índice de atividade pozolânica da CCA realizou-se o ensaio de acordo com a NBR 5751 (ABNT, 1992a), que considera a determinação da atividade pozolânica utilizando a cal. O índice de consistência foi determinado através do uso da flow table seguindo-se as prescrições da NBR 13276 (ABNT, 1995a), o qual determina a quantidade de água para moldagem das argamassas; neste ensaio foram feitas entre 5 a 7 tentativas buscando-se o valor exigido pela norma e, depois de encontrado, 3 repetições.

Após a caracterização da cinza e da determinação do índice de consistência, foram moldados corpos de prova referentes às argamassas de assentamento no traço 1:2:9 (cimento:cal:areia), em massa, e as argamassas alternativas com CCA nas proporções de 6, 9, 15, 20 e 30\%, como substituto parcial do cimento. Os corpos de prova foram confeccionadas em moldes cilíndricos com dimensões de $5 \mathrm{~cm}$ de diâmetro e $10 \mathrm{~cm}$ de altura, de acordo com os procedimentos estabelecidos pela NBR 7215 (ABNT, 1996), ou seja, foram moldados 5 corpos de prova para cada traço. $O$ proporcionamento utilizado para moldagem de cada argamassa pode ser observado na Tabela 1, sendo os valores da cal de $1,09 \mathrm{~kg}$ e areia de $12,22 \mathrm{~kg}$. A cura dessas argamassas foi realizada em câmara úmida saturada com cal para evitar carbonatação, em períodos de 28, 63 e 91 dias.

Avaliou-se a influência da cinza da casca do arroz nas argamassas a partir dos traços estudados em cada período de

Tabela 1. Proporcionamento de cada argamassa estudada

\begin{tabular}{cccc}
\hline \multirow{2}{*}{ Traços } & CCA & \multicolumn{1}{c}{ Cimento } & CCA \\
\cline { 3 - 5 } & $(\%)$ & \multicolumn{2}{c}{$\mathbf{( k g )}$} \\
& 0 & 1,00 & 0 \\
& 6 & 0,94 & 0,022 \\
& 9 & 0,91 & 0,033 \\
& 15 & 0,85 & 0,055 \\
& 20 & 0,80 & 0,073 \\
& 30 & 0,70 & 0,110 \\
\hline
\end{tabular}

cura, através da determinação das propriedades físicas e mecânicas dos corpos de prova, com os ensaios de densidade de massa NBR 13280 (ABNT, 1995b), absorção por imersão em água NBR 9778 (ABNT, 1987) e resistência a compressão simples NBR 7215 (ABNT, 1996).

\section{RESULTADOS E DISCUSSÃO}

A curva de distribuição granulométrica da CCA está apresentada na Figura 1; analisando-a observa-se que a curva tem comportamento modal com diâmetro de partículas variando de $0,1 \mu \mathrm{m}$ a $100 \mu \mathrm{m}$, com tamanho de partículas correspondente a $\mathrm{D}_{10} \operatorname{com} 3,52 \mu \mathrm{m}, \mathrm{D}_{50} \operatorname{com} 16,62 \mu \mathrm{m}, \mathrm{D}_{90}$ com 49,93 $\mu$ me diâmetro médio de 22,24 ìm. Para o diâmetro de $5 \mu \mathrm{m}$ obteve-se o valor de $15,75 \%$ indicando provável presença de aglomerantes, ou seja, o material apresenta tamanho de partículas que lhe permite características de um material cimentante. Della et al. (2006) obtiveram a partir da casca de arroz lixiviada uma cinza de menor granulometria com diâmetro médio de $17,37 \mu \mathrm{m}$.

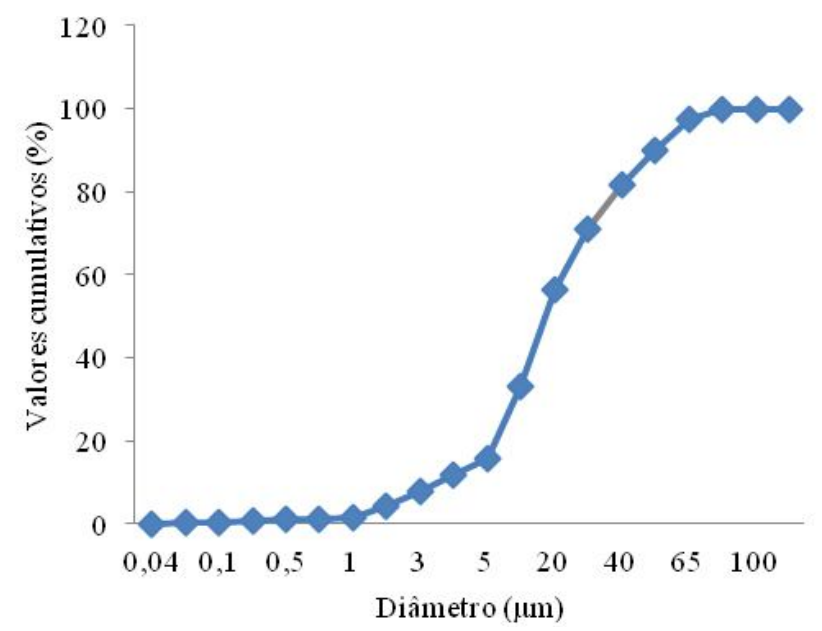

Figura 1. Curva de distribuição granulométrica da cinza da casca do arroz

As propriedades físicas da cinza da casca do arroz são apresentadas na Tabela 2, observando-se o baixo valor para massa unitária de $0,40 \mathrm{~g} \mathrm{~cm}^{-3}$, sendo aproximadamente similar ao obtido por Molin et al. (2001) e Souza (2008), de 0,46 $\mathrm{g} \mathrm{cm}^{-3}$, indicando que a cinza possui baixa densidade e é considerada material poroso. A superfície específica foi de $10197,38 \mathrm{~cm}^{2} \mathrm{~g}^{-1}$ superior ao estabelecido por norma e inferior aos valores encontrados por Della et al. (2001), Souza (2008) e Tiboni (2007) de $17700,14790,39$ e $14302,30 \mathrm{~cm}^{2} \mathrm{~g}^{-1}$, respectivamente, fato justificado em virtude da CCA estudada nesta pesquisa não ter passado por nenhum tratamento, razão porque é considerada residual. Analisando conjuntamente o resultado conclui-se que a cinza pode ser usada como substituto parcial do cimento em argamassas, pois a área específica obtida foi

Tabela 2. Propriedades físicas da cinza da casca do arroz

\begin{tabular}{lcc}
\hline \multicolumn{1}{c}{ Ensaio } & Limites & Resultados obtidos \\
Massa unitária $\left(\mathrm{g} \mathrm{cm}^{-3}\right)$ & - & 0,40 \\
Superfície es pecífica (Blaine) $\left(\mathrm{cm}^{2} \mathrm{~g}^{-1}\right)$ & $\geq 2600$ & 10197,38 \\
\hline
\end{tabular}


superior à do cimento $\left(5023,28 \mathrm{~cm}^{2} \mathrm{~g}^{-1}\right) \mathrm{e}$ da cal $\left(6558,21 \mathrm{~cm}^{2} \mathrm{~g}^{-1}\right)$ utilizados na pesquisa.

Tem-se, na Figura 2, o difratograma de raios X da CCA; analisando-a, observa-se que a amostra de CCA apresenta uma banda característica de um material amorfo, em que o óxido predominante é o dióxido de silício (sílica), estando os demais óxidos presentes sob a forma de solução sólida. O comportamento do DRX pode ser explicado visto que esta cinza não passou por tratamento térmico algum, para eliminação do carbono existente (submetida a altas temperaturas), fazendo com que não houvesse a provável cristalização das partículas. Em suas pesquisas Liou (2004), Gonçalves et al. (2009), Habeeb \& Mahmud (2010) e Vasconcelos \& Akasaki (2010) observaram comportamento similar para cinza de casca de arroz utilizada.

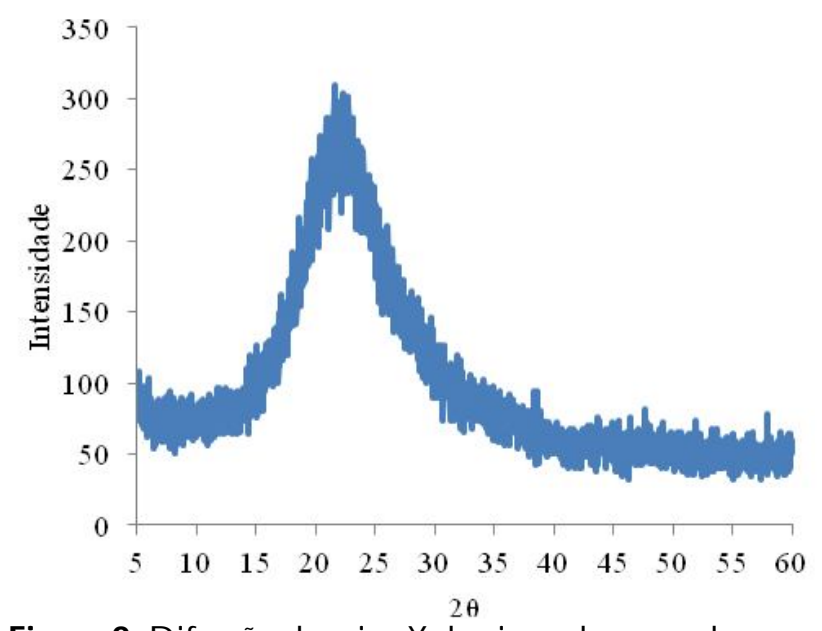

Figura 2. Difração de raios $X$ da cinza da casca do arroz

$\mathrm{Na}$ análise térmica gravimétrica de CCA, Figura 3, a amostra apresentou perda de massa total de $13,7 \%$, correspondente à perda de água adsorvida até $200{ }^{\circ} \mathrm{C}$; para as temperaturas superiores a 200 até $1000{ }^{\circ} \mathrm{C}$, verificou-se perda de massas, correspondente à matéria orgânica.

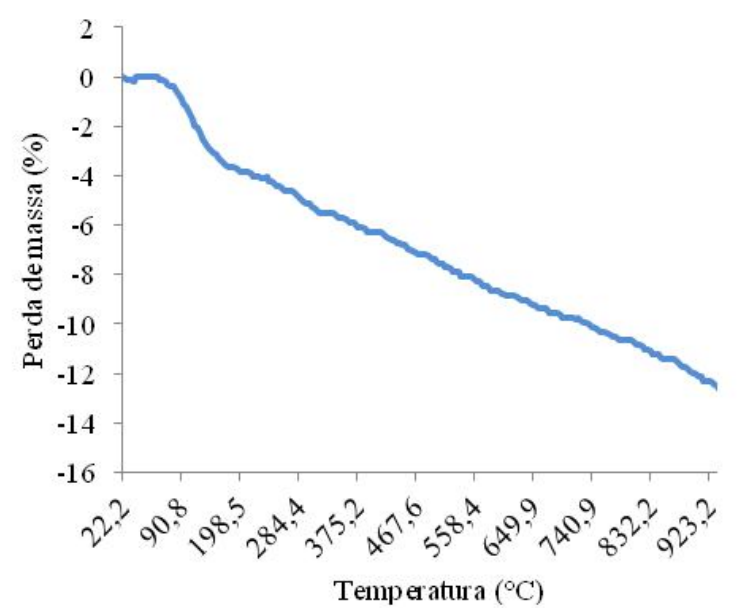

Figura 3. Curva da análise térmica gravimétrica da cinza da casca do arroz

Na Tabela 3 está apresentada a composição química da CCA estudada nesta pesquisa. Analisando os valores da Tabela 3, nota-se elevado teor de dióxido de silício $\left(\mathrm{SiO}_{2}\right)$ conferindo, a este material, características de uma pozolana, de acordo com pesquisas de Tiboni (2007), Souza (2008), Cordeiro et al. (2009b) e Silva et al. (2009).

Tabela 3. Composi ção química da cinza da casca do arroz

\begin{tabular}{lc}
\hline Componentes & Resultados (\%) \\
$\mathrm{SiO}_{2}$ & 83,41 \\
$\mathrm{~K}_{2} \mathrm{O}$ & 2,53 \\
$\mathrm{Al}_{2} \mathrm{O}_{3}$ & 1,97 \\
Demais óxidos & 2,54 \\
Perda ao fogo & 9,55 \\
\hline
\end{tabular}

$\mathrm{Na}$ Tabela 4 se encontram os resultados das propriedades químicas exigidas para que o material seja considerado pozolânico. Analisando os dados da Tabela 4, vê-se que todos os valores atendem às exigências estabelecidas pela NBR 12653 (ABNT, 1992b) e ASTM (1991), para caracterizar um material pozolânico e com características de aglomerante. O elevado teor de perda ao fogo pode ser um fator atenuante da quantidade de sílica, e estar diretamente relacionado ao alto teor de carbono existente na CCA. O valor obtido para o tamanho das partículas maiores que 45 ìm, foi inferior ao estabelecido por norma, caracterizando a CCA como material muito fino confirmando, mais uma vez, sua pozolanicidade.

Tabela 4. Propriedades químicas para o índice de atividade pozolânica

\begin{tabular}{lccc}
\hline \multicolumn{1}{c}{ Propriedades } & $\begin{array}{c}\text { NBR 12653 } \\
\text { (ABNT, 1992b) }\end{array}$ & $\begin{array}{c}\text { ASTM } \\
\text { (1991) }\end{array}$ & $\begin{array}{c}\text { Resultados } \\
\text { (\%) CCA }\end{array}$ \\
$\mathrm{SiO}_{2}+\mathrm{Al}_{2} \mathrm{O}_{3}+\mathrm{Fe}_{2} \mathrm{O}_{3}(\%$ min.) & 70 & 70 & 85,69 \\
$\mathrm{SO}_{3}(\%$ máx.) & 4 & - & 0,31 \\
Teor de umidade $(\%$ máx.) & 3 & - & - \\
Perda ao fogo $(\%$ máx.) & 10 & 10 & 9,55 \\
Partículas $>45 \mu$ m (\% máx.) & 34 & 34 & 13,77 \\
\hline
\end{tabular}

Obteve-se, para o índice de atividade pozolânica da cinza da casca do arroz, o valor de 6,3 MPa, maior que o estabelecido pelas normas NBR 5751 (ABNT, 1992a) e ASTM (2009), de 6,0 e 2,4 MPa, respectivamente. Então, a cinza em questão atende a um dos critérios para ser caracterizada como material pozolânico e utilizada como substituto parcial do cimento.

Na Tabela 5 estão apresentados os valores para a relação água/aglomerante, teor de água e índice de consistência das argamassas. Analisando os resultados obtidos na Tabela 5 para a relação água/aglomerante observa-se que, conforme aumenta a porcentagem de finos há, também, um aumento na quantidade de água utilizada para se obter o índice de

Tabela 5. Relação água/aglomerante, teor de água e índice de consistência das argamassas

\begin{tabular}{crrrc}
\hline Traços & $\begin{array}{c}\text { CCA } \\
\text { (\%) }\end{array}$ & RAA & $\begin{array}{c}\text { TA } \\
(\%)\end{array}$ & $\begin{array}{c}\text { IC } \\
\text { (mm) }\end{array}$ \\
& 0 & 1,48 & 21,6 & 251,33 \\
& 6 & 1,52 & 21,8 & 258,67 \\
1:2:9 (cimento:\%CCA:cal:areia) & 9 & 1,54 & 22,0 & 255,67 \\
& 15 & 1,61 & 22,6 & 260,67 \\
& 20 & 1,63 & 22,6 & 257,33 \\
& 30 & 1,69 & 22,8 & 253,03 \\
\hline
\end{tabular}

CCA - Cinza de casca de arroz, RAA - Relação água/aglomerante, TA - Teor de água, IC - Índice de consistência 
consistência desejado. Esta ocorrência pode ser atribuída, provavelmente, à elevada superfície específica dos materiais aglomerantes, haja vista serem a cinza da casca do arroz $\left(10197,38 \mathrm{~cm}^{2} \mathrm{~g}^{-1}\right)$ e a cal $\left(6558,21 \mathrm{~cm}^{2} \mathrm{~g}^{-1}\right)$ materiais mais finos que o cimento $\left(5023,28 \mathrm{~cm}^{2} \mathrm{~g}^{-1}\right)$, existindo uma relação entre a quantidade de finos e a água necessária. Os índices de consistência obtidos atenderam ao limite estabelecido pela NBR 13276 (ABNT, 1995a) de $255 \pm 10 \mathrm{~mm}$.

Os valores das densidades de massa dos corpos de prova das argamassas incorporadas com CCA no estado endurecido para o traço 1:2:9 (cimento:\%CCA:cal:areia), em massa, estão na Figura 4.

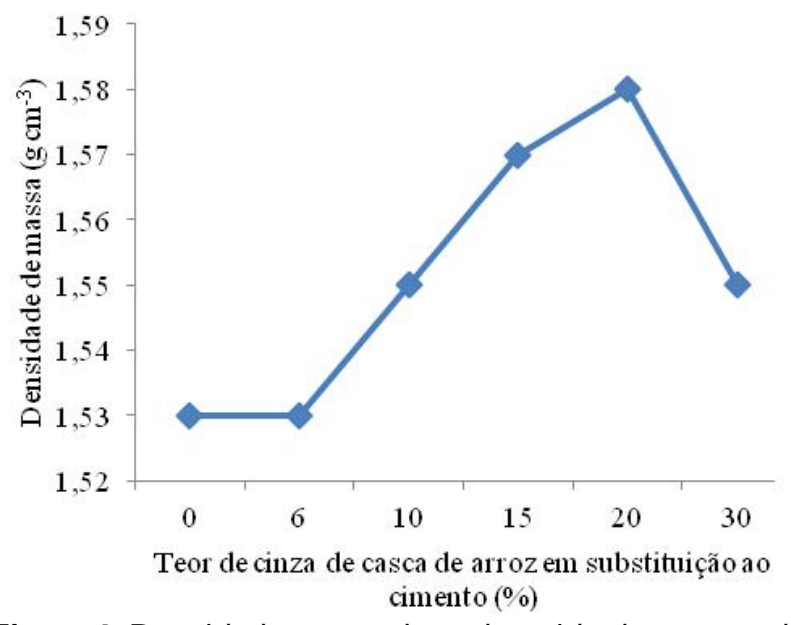

Figura 4. Densidade no estado endurecido dos corpos de prova das argamassas 1:2:9

Observa-se, de acordo com a Figura 4, que os corpos de prova com 15 e $20 \%$ de CCA apresentaram maior valor de densidade que os demais. Os valores obtidos podem ser justificados pelo fato das adições minerais agirem na argamassa e tornarem a matriz da pasta mais densa e consequentemente menos porosa, o que favorece a elevação da resistência mecânica devido ao preenchimento dos vazios. Os corpos de prova das argamassas com 6\% de CCA obtiveram valores iguais aos dos corpos de prova de referência, por não ter ocorrido o refinamento dos poros em que, de acordo com Tiboni (2007) e Souza (2008), o percentual de substituição de 6\% de CCA não é suficiente para que as reações pozolânicas ocorram.

Na Figura 5 estão apresentados os resultados obtidos para a absorção de água dos corpos de prova das argamassas incorporadas com CCA para traço 1:2:9 (cimento:\%CCAcal:areia), após períodos de cura de 28, 63 e 91 dias.

Verifica-se, de acordo com a Figura 5, que o valor da absorção de água dos corpos de prova decresceu para os períodos de cura de 28 e 91 dias, reduzindo em aproximadamente $6 \%$ aos 91 dias; após 63 dias de cura constatou-se um sutil acréscimo no teor de absorção de água, de aproximadamente $2 \%$, podendo tal fato ter ocorrido, provavelmente, por se ter grande quantidade de agregado miúdo na constituição dessas argamassas, favorecendo um índice maior de vazios. Souza (2008) obteve, em sua pesquisa, o mesmo comportamento após 63 dias de cura para os corpos de prova das argamassas 1:8 (cimento:areia) com percentuais de cinza de casca de arroz como constituinte.

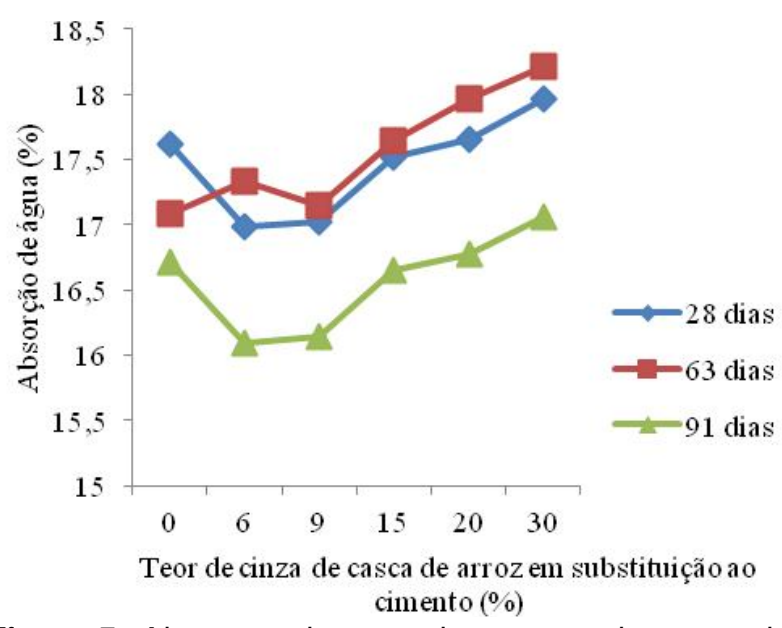

Figura 5. Absorção de água dos corpos de prova das argamassas incorporadas com CCA para o traço 1:2:9, após períodos de cura de 28, 63 e 91 dias

Observa-se, após 28 e 91 dias de cura, que os corpos de prova com 6,9 e $15 \%$ apresentaram melhor comportamento que o traço de referência podendo ser justificado, provavelmente, pelo fato de que, com o decorrer do tempo de cura, há uma acomodação maior das partículas (efeito de empacotamento) constatando-se, desta forma, diminuição da porosidade e, consequentemente, diminuição também na absorção da água.

Os valores da resistência a compressão simples dos corpos de prova das argamassas incorporadas com CCA para o traço 1:2:9 (cimento:\%CCA:cal:areia), após períodos de cura de 28, 63 e 91 dias, estão apresentados na Figura 6.

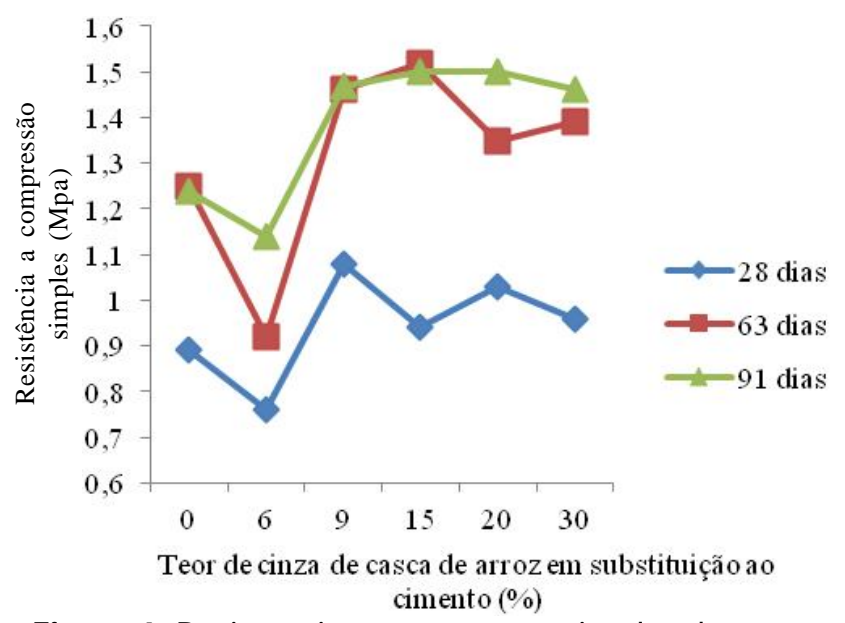

Figura 6. Resistência a compressão simples dos corpos de prova das argamassas incorporadas com CCA para 0 traço 1:2:9, após períodos de cura de 28, 63 e 91 dias

Observa-se, na Figura 6, aumento na resistência a compressão para todos os períodos de cura em que os corpos de prova contendo CCA, apresentaram valores superiores ao da argamassa de referência, exceto com 6\%; este aumento pode ser atribuído, provavelmente, à reação da CCA com o hidróxido de cálcio formando o C-S-H, material resistente e estável, que favorece o aumento da resistência e diminuição da permeabilidade devido ao processo de refinamento dos poros (reação pozolânica). 
Em relação aos 28 dias, o material apresentou reação pozolânica pois os corpos de prova das argamassas contendo CCA apresentaram valores de resistência superiores aos dos corpos de prova da argamassa de referência. Neste caso, podese considerar que a reação pozolânica não foi tão lenta quanto se espera de uma reação pozolânica comum. Silva et al. (2009) encontraram, aos 7 dias, para argamassas com CCA, desempenho mecânico superior ao das argamassas sem CCA.

Segundo Malhotra \& Metha (1996), o bom desempenho das argamassas com 9, 15, 20 e $30 \%$ pode ser justificado pelo fato de haver preenchimento dos vazios da argamassa, denominado efeito filler, quando há incorporação de resíduos, aumentando o empacotamento das partículas e diminuindo, consequentemente, os vazios, favorecendo positivamente a resistência a compressão simples. Dentre as argamassas estudadas a que apresentou melhor comportamento mecânico foi a com $15 \%$ de CCA em substituição ao cimento, após os períodos de cura de 63 e 91 dias.

\section{Conclusões}

1. A cinza da casca do arroz foi caracterizada como material pozolânico, por apresentar comportamento amorfo, elevado teor de sílica e índice de atividade pozolânica superior ao estabelecido por norma, conferindo-lhe boa reatividade e, por isso mesmo, considerada adequada para uso como aglomerante na produção de argamassas.

2. A quantidade de água utilizada para produção dos corpos de prova teve um aumento diretamente proporcional à quantidade de finos de cada mistura confeccionada, para manter a trabalhabilidade desejada.

3. A densidade de massa no estado endurecido dos corpos de prova das argamassas com cinza da casca do arroz apresentou melhor desempenho que as argamassas de referência (sem cinza da casca do arroz).

4. O índice de absorção de água dos corpos de prova das argamassas diminuiu de acordo com o aumento no tempo de cura.

5. A resistência a compressão simples apresentou aumento no desempenho para todas as argamassas até os 63 dias de cura; após este período, aos 91 dias de cura não se observou aumento significativo na resistência.

\section{LITERATURA CITADA}

ABNT - Associação Brasileira de Normas Técnicas. NBR 9778: Argamassa e concreto endurecidos - Determinação da absorção de água por imersão, índice de vazios e massa específica. Rio de Janeiro: ABNT, 1987. 5p.

ABNT - Associação Brasileira de Normas Técnicas. NBR 5751: Determinação do índice de atividade pozolânica com cal. Rio de Janeiro: ABNT, 1992a. 3p.

ABNT - Associação Brasileira de Normas Técnicas. NBR 12653: Materiais Pozolânicos - Exigências químicas e físicas. Rio de Janeiro: ABNT, 1992b. 5p.
ABNT - Associação Brasileira de Normas Técnicas. NBR 13276: Argamassa para assentamento e revestimento de paredes e tetos - Preparo da mistura e determinação de consistência. Rio de Janeiro: ABNT, 1995a. 2p.

ABNT - Associação Brasileira de Normas Técnicas. NBR 13280: Argamassa para assentamento e revestimento de paredes e tetos - Determinação da densidade de massa aparente no estado endurecido. Rio de Janeiro: ABNT, 1995b. 2p.

ABNT - Associação Brasileira de Normas Técnicas. NBR 7215: Cimento Portland - Determinação da resistência à compressão. Rio de Janeiro: ABNT, 1996. 8p.

Agarwal, S. K. Pozzolanic activity of various siliceous materials. Cement and Concrete Research, v.36, p.1735-1739, 2006.

ASTM - American Society for Testing and Materials. ASTM C 618: Flay ash and raw or calcined natural pozzolan for use as a mineral admixture in Portland cement concrete: Annual Book of ASTM Standards. Philadelphia: ASTM, 1991.3p.

ASTM - American Society for Testing and Materials. ASTM C 1707: Standard specification for specification pozzolanic hydraulic line for structural purposes: Annual Book of ASTM Standards. Philadelphia: ASTM, 2009. 3p.

Barboza, A. S. R.; Barbirato, J. C. C.; Silva, M. M. C. P. Avaliação do uso de bambu como material alternativo para a execução de habitação de interesse social. Ambiente Construído, v.8, p.115-129, 2008.

Bui, D. D.; Hu, J.; Stroeven, P. Particle size effect on the strength of rice husk ash blended gap-graded Portland cement concrete. Cement and Concrete Composites, v.27, p.357-366, 2005.

Carmo, J. B. M.; Portella, K. F. Estudo comparativo do desempenho mecânico da sílica ativa e do metacaulim como adições químicas minerais em estruturas de concreto. Cerâmica, v.54, p.309-318, 2008.

Cordeiro, G. C.; Toledo Filho, R. D.; Fairbairn, E. M. R. Caracterização de cinza do bagaço de cana-de-açúcar para emprego como pozolana em materiais cimentícios. Química Nova, v.32, p.82-86, 2009a.

Cordeiro, G. C.; Toledo Filho, R. D.; Fairbairn, E. M. R. Influência da substituição parcial de cimento por cinza ultrafina da casca de arroz com elevado teor de carbono nas propriedades do concreto. Ambiente Construído, v.9, p.99107, 2009b.

Della, V. P.; Hotza, D.; Junkes, J. A.; Oliveira, A. P. N. Estudo comparativo entre sílica obtida por lixívia ácida da casca de arroz e sílica obtida por tratamento térmico da cinza de casca de arroz. Química Nova, v.29, p.1175-1179, 2006.

Della, V. P.; Kühn, I.; Hotza, D. Caracterização de cinza de casca de arroz para uso como matéria-prima na fabricação de refratários de sílica. Química Nova, v.24, p.778-782, 2001.

Della, V. P.; Kühn, I.; Hotza, D. Reciclagem de resíduos agroindustriais: Cinza de casca de arroz como fonte alternativa de sílica. Cerâmica Industrial, v.10, p.22-25, 2005.

Di Campos, M. S.; Barbosa, N. P.; Savastano Jr., H. Swine deep bedding ashes as a mineral additive for cement based mortar. Scientia Agricola, v.65, p.109-115, 2008.

Folleto, E. L.; Hoffman, R.; Hoffman, R. S.; Portugal Jr., V. L.; Jahn, S. L. Aplicabilidade das cinzas da casca de arroz. Química Nova, v.28, p.1055-1060, 2005. 
Ganesan, K.; Rajagopal, K.; Thangavel, K. Rice husk ash blended cement: Assessment of optimal level of replacement for strength and permeability properties of concrete. Construction and Building Materials, v.22, p.1675-1683, 2008.

Ghavami, K.; Marinho, A. B. Propriedades físicas e mecânicas do colmo inteiro do bambu da espécie Guadua angustifolia. Revista Brasileira de Engenharia Agrícola e Ambiental, v.9, p.107-114, 2005.

Gonçalves, G. E.; Sabioni, A. C. S.; Ferraz, W. B.; Costa, G. M.; Brito, W.; Dias, J. A.; Garcia, F. A. C. Síntese e caracterização de mulita utilizando sílica obtida da casca de arroz. Revista Escola de Minas, v.62, p.367-372, 2009.

Habeeb, G. A.; Mahmud, H. B. Study on properties of rice husk ash and its use as cement replacement material. Materials Research, v.13, p.185-190, 2010.

Isaia, G. C.; Gastaldini, A. L. G.; Meira, L.; Duart, M.; Zerbino, R. Viabilidade do emprego de cinza de casca de arroz natural em concreto estrutural. Parte I: propriedades mecânicas e microestrutura. Ambiente Construído, v.10, p.121-137, 2010.

Kieling, A.; Caetano, M. O.; Kulakoswki, M. P.; Kazmierczak, C. S. Influência da adição de cinza de casca de arroz na aderência de argamassas de revestimento. Ensaios Tecnológicos, v.5, p.157-170, 2009.

Lima, M. S.; Menezes, R. R.; Neves, G. de A.; Nascimento, J. W. B. do; Leal, A. F. Utilização do resíduo de caulim em blocos de vedação. Revista Escola de Minas, v.61, p.285-290, 2008.

Lima, S. A.; Rossignolo, J. A. Estudo das características químicas e físicas da conza da casca da castanha de caju para uso em materiais cimentícios. Acta Scientiarum Technology, v.32, p.383-389, 2010.

Liou, T. H. Preparation and characterization of nano-structured sílica from rice husk. Materials Science and Engineering, v.364, p.313-323, 2004.

Malhotra, V. M.; Mehta, P. K. Pozzolanic and cementitious materials. 1.ed. Amsterdam: Advances in Concrete Technology, 1996. 191p.

Menezes, R. R.; Fagury Neto, E.; Fernandes, M. C.; Souto, P. M.; Kiminami, R. H. G. A. Obtenção de mulita porosa a partir da sílica da casca de arroz e acetato de alumínio. Revista Cerâmica, v.54, p.245-252, 2008.

Menezes, R. R.; Neves, G. A.; Souza, J.; Melo, W. A.; Ferreira, H. S.; Ferreira, H. C. Atividade pozolânica dos resíduos do beneficiamento do caulim para uso em argamassas para alvenaria. Revista Brasileira de Engenharia Agrícola e Ambiental, v.13, p.795-801, 2009.

Molin, D. C. C. dal; Mattos, L. R. S.; Carneiro, A. Caracterização das argamassas para revestimento externo utilizadas em Belém/PA: estudo do comportamento no estado fresco. In: Simpósio Brasileiro de Tecnologia das Argamassas, 4, 2001, Brasília. Anais... Porto Alegre: ANTAC, 2001. CD Rom.

Nair, D. G.; Fraaij, A.; Klaassen, A. A. K.; Kentgens, A. P. M. A structural investigation relating to the pozzolanic activity of rice rusk ashes. Cement and Concrete Research, v.40, p.861-869, 2008.

Nair, D. G.; Jagadish, K. S.; Fraaij, A. Reactive pozzolanas from rice husk ash: an alternative to cement for rural housing. Cement and Concrete Research, v.36, p.1062-1071, 2006.
Paula, M. O.; Tinôco, I. de F. F.; Rodrigues, C. S.; Silva, E. N.; Souza, C. F. Potencial da cinza do bagaço da cana-de-açúcar como material de substituição parcial de cimento Portland. Revista Brasileira de Engenharia Agrícola e Ambiental, v.13, p.353-357, 2009.

Pouey, M. T. F.; Molin, D. C. C. dal; Bergmann, C. P. Avaliação de diferentes processos de moagem de cinzas de casca de arroz residuais com diferentes características mineralógicas através do índice de atividade pozolânica. In: Congresso Brasileiro do Concreto, 49, 2007. Bento Gonçalves. Anais... São Paulo: IBRACON, 2007. CD Rom.

Ramezanianpour, A. A.; Mahdikhani, M.; Ahmadibeni, Gh. The effect of rice husk ash on mechanical properties and durability of sustainable concretes. International Journal of Civil Engineerng, v.7, p.83-91, 2009.

Rashid, M. H.; Molla, M. K. A.; Ahmed, T. U. Mortar incorporating rice husk ash: strength and porosity. European Journal of Scientific Research, v.40, p.471-477, 2010.

Rodrigues M. S.; Beraldo A. L. Caracterização física e mecânica de argamassas à base de cimento Portland e cinza de casca de arroz residual. Engenharia Agrícola, v.30, p.193-204, 2010.

Sensale, G. R. Strength development of concrete with rice husk ash. Cement and Concrete Composites, v.28, p.158-160, 2006.

Silva, E. J.; Akasaki, J. L.; Dasnoy, J. Influência das variáveis envolvidas no plantio de arroz nas características da cinza de casca de arroz. Ambiente Construído, v.9, p.67-82, 2009.

Silva, E. J.; Tashima, M. M.; Akasaki, J. L. Estudo de reações expansivas em argamassas de cimento Portland com cinza de casca de arroz (CCA). HOLOS Environment, v.7, p.72-86, 2007.

Souza, J. Estudo da durabilidade de argamassas utilizando cinzas e casca de arroz no traço. Campina Grande: UFCG, 2008. 160p. Tese Doutorado

Tashima, M. M.; Silva, C. A. R. L.; Akasaki, J. L. Concreto com adição de cinza de casca de arroz (CCA) obtida através de um processo de combustão não controlada. In: Jornadas Sud-Americanas de Ingeniería Estructural, 31, 2004, Mendonza, Argentina. Anais... Mendoza, Argentina: Facultad de Ingeniería, Universidad Nacional de Cuyo, 2004. CD Rom.

Tiboni, R. Autilização da cinza da casca de arroz de termoelétrica como componente do aglomerante de compósitos à base de cimento Portland. São Carlos: USP, 2007. 196p. Dissertação Mestrado

Toralles-Carbonari, B. M.; Cavalaro, S. H.; Castanha, J. C. M.; Guacelli, P. A. G.; Silva, C. C. Utilização do método ultrasônico para avaliação da performance do concreto de alto desempenho. Revista Ibracon de Estruturas e Materiais, v.3, p. 494-511, 2010.

Vasconcelos, A. R. B.; Akasaki, J. L. Análise da durabilidade do concreto de alto desempenho com adição de cinza de casca de arroz e borracha de pneu. Ambiente Construído, v.10, p.77-90, 2010.

Zerbino, R.; Giaccio, G.; Isaia, G. C. Concrete incorporating rice husk ash without processing. Construction \& Building Materials, v.25, p.371-378, 2011. 